\title{
Impulso à verdade e impulso artístico: uma leitura de Sobre verdade e mentira no sentido extra-moral
}

\author{
Thelma Lessa da Fonseca
}

Professora do Departamento de Filosofia e Metodologia das Ciências da UFSCar

\begin{abstract}
Resumo: Em Ueber Wabrheit und Luege in aussermoralischen Sinne, a discussão é travada em torno de duas noções, cada qual sinalizando uma atitude específica em relação à linguagem: impulso à verdade e impulso artístico. $\mathrm{O}$ artigo que se segue parte da distinção entre essas duas noções com o objetivo de especificar que noção de verdade está em jogo na crítica nietzschiana feita nesse texto.
\end{abstract}

Palavras-chave: impulso à verdade, impulso artístico, consciência, linguagem.
Abstract: In Ueber Wabrheit und Luege in aussermoralischen Sinne one finds a discussion between two notions, each of them pointing out to a specific attitude regarding language: truth drive and artistic drive. This paper takes into account these two conceptions with the intention of specifying what notion of truth is at stake in the Nietzschean critique carried out in this text.

Key-words: truth drive, artistic drive, consciousness, language.

Somos instados ao cumprimento dessa dupla tarefa (dar realidade ao necessário em nós e submeter a realidade fora de nós à lei da necessidade) por duas forças opostas, que nos impulsionam para a realização de seus objetos e que poderíamos chamar convenientemente de impulsos. ${ }^{1}$

O ensaio introdutório chamado Sobre verdade e mentira no sentido extra-moral toma, como ponto de partida, a pergunta pela origem do Trieb zur Wahrheit. Inicialmente, tal noção possui um sentido bastante abrangente de "interesse pela verdade" ou "propensão à busca da verdade". Aos poucos, o texto deixa entrever

1. Schiller, F. A educação estética do homem, carta XII. Trad. de Roberto Schwartz e Márcio Suzuki. São Paulo: Iluminuras, 1990, p. 67. 
que esse interesse parte de uma suposição, a saber, a suposição de que a inteligência humana seja capaz de nos levar a conhecer algo das coisas em si mesmas. Isso pode ser inferido pelo teor da crítica que Nietzsche desenvolve ao conhecimento, pois esta crítica é dedicada a destruir os fundamentos da expectativa de que o conhecimento racional possa representar-se algo das coisas em si mesmas, o que é freqüentemente interpretado como crítica a uma idéia de verdade como adequação e que, portanto, reinsere Nietzsche no contexto das discussões sobre o conhecimento travadas pelas chamadas "filosofias da representação". 2

São dois os principais argumentos utilizados por Nietzsche que permitem entender que crítica se contrapõe a uma concepção de conhecimento assim descrita: em primeiro lugar, há a idéia de que todo conceito é antropomórfico e, ao invés de refletir algo da "essência" das coisas, apenas revela elementos projetados pelo próprio homem no "mundo". Tal idéia está apoiada em uma concepção de linguagem como originalmente metafórica. Em segundo lugar, o autor defende uma concepção do intelecto a partir da qual tudo aquilo que ele pode abranger passa pelo filtro de interesses de auto-conservação da coletividade. Assim, não haveria objetividade possível, pois não haveria conhecimento desinteressado. Dessa forma, Nietzsche estaria operando, em Wabrheit und Luege, com as idéias de verdade como adequação e de conhecimento como conformidade, ainda que para recusá-las.

Se conhecimento não pode abranger, por sua constituição e utilidade original, as coisas em si mesmas, então cabe perguntar pela origem dessa expectativa. Trata-se, dessa forma, de uma pergunta pela origem da pretensão do conhecimento racional, pergunta essa que se sustenta sobre a constatação de seus limites.

2. Habermas, J. "La Critica Nihilista del Conocimiento en Nietzsche". In: ____. Sobre Nietzsche y otros ensayos. Trad. de Carmen G. Trevijano e Silverio Cerra. Madri: Tecnos, 1982 (utilizou-se, aqui, a tradução espanhola do ensaio que serviu como epílogo à publicação da Suhrkamp de uma antologia de escritos sobre teoria do conhecimento em Nietzsche). Neste artigo, Habermas trata especificamente de Wabrheit und Luege e reconhece haver aí uma teoria do conhecimento que, mesmo implícita, comprometeria o autor com a noção de verdade como adequação e, conseqüentemente, com as chamadas "filosofias da representação". Cf. op. cit., pp. 44-52. 
Detenhamo-nos aqui em compreender aqueles dois argumentos para, em seguida, investigar o sentido da pergunta pelo Trieb zur Wabrbeit feita por Nietzsche.

Ao reafirmar o caráter arbitrário da linguagem que fornece os alicerces do conhecimento racional, Nietzsche retoma a argumentação de seu Curso de retórica para mostrar que a linguagem tem uma origem trópica e que não há qualquer relação de necessidade entre as palavras e aquilo que elas pretendem significar:

Um estímulo nervoso, primeiramente transposto em uma imagem! Primeira metáfora. A imagem, por sua vez, modelada em um som! Segunda metáfora. (...) Acreditamos saber algo das coisas mesmas, se falamos de árvores, cores, neve e flores, e no entanto não possuímos nada mais do que metáforas de coisas, que de nenhum modo correspondem às entidades de origem. ${ }^{3}$

Apóia-se sobre três pontos a argumentação em favor da idéia de que toda linguagem é metafórica. Em primeiro lugar, conforme está dito no trecho acima, quando qualificamos um objeto qualquer pensamos estar denominando uma qualidade da própria coi-

3. Nietzsche, F. Sobre verdade e mentira no sentido extra-moral. In: Sämtliche Werke. Kritische Studienausgabe. vol. I. Org. de Giorgio Colli $\mathrm{e}$ Mazzino Mortinari. Berlim: Walter de Gruyter, 1980. p. 881. Sempre que possível, serão utilizadas as traduções de Rubens Rodrigues Torres Filho de Nietzsche, F. Obras Incompletas. São Paulo: Abril Cultural, 1978. Nesse trecho transparece novamente a idéia de Gerber de que a palavra é uma transposição de um estímulo nervoso em sons: "Es muss uebrigens schon an dieser Stelle auf den Unterschied zwischen dem Inhalt der Empfindung und dem Inhalt ihrer Aeusserung durch den Laut hingewiesen werden. Die Empfindung naemlich, wie sie unmittelbar, durch irgend einen Nervenreiz hervor gerufen wird, nimmt zwar das Ding selbst, vom dem dieser Reiz ausgeht, nicht in sich auf, aber sie steht doch mit ihm in einen direkten, sinnlichen Bezuge, erscheint von ihm abhaengig, gleichsam von ihm erfuellt. Wird aber diese Empfindung nach aussen hin dargestellt, so ist der Zusammenhang mit dem Reiz veranlassenden Ding nur noch ein mittelbarer, und die Darstellung laesst nothwendig das Ding ausser Acht, und damit auch die genauere, individuelle Bestimmtheit des Reizes". Meijers, A. Die Sprache als Kunst. Berlim: Walter de Gruyter, 1988, p.157; cf. tabela de concordância em Meijers, A.; Stingelin, M. "Gerber und Nietzsche - Konkordanz”. In: Nietzsche Studien, v. XVII, 1988. 
sa, como se tal propriedade fosse conhecida por nós “(...) de outra forma que de uma maneira inteiramente subjetiva". No entanto, apenas temos acesso a estímulos internos provavelmente constituídos de um material absolutamente diverso daquele que constitui a suposta "coisa" que o desencadeou.

Em segundo lugar, cada denominação reflete a eleição arbitrária de uma característica, como se tal característica fosse exclusiva daquela entidade a que buscamos nos referir. O exemplo utilizado pelo autor aqui é um exemplo retomado do Curso de Retórica: "Falamos de uma Schlange (cobra): a designação não se refere a nada mais do que o enrodilhar-se, e portanto poderia também caber ao verme. Que delimitações arbitrárias, que preferências unilaterais, ora por esta, ora por aquela propriedade de uma coisa!" ${ }^{4} \mathrm{O}$ exemplo demonstra que uma mesma denominação seria adequada para referir-se a coisas distintas. Mas demonstra ainda que nossa excitação interna consiste num composto de diversos elementos, os quais, por sua vez, são arbitrariamente separados e, a partir desse composto, um desses elementos, ou um grupo deles, é escolhido para fixar a denominação.

Há ainda, em terceiro lugar, o caso em que os mesmos objetos são denominados por diferentes nomes, tal como nos mostram as diferenças entre as inúmeras línguas. Disso conclui Nietzsche que não existe "expressão adequada".

4. Nietzsche, F. Sobre verdade e mentira no sentido extra-moral. In: Sämtliche Werke. Kritische Studienausgabe, vol. I, p. 881. Também esse exemplo provém de Gerber, conforme mostra Meijers e Stingelin: "Wenn nun z.B. die Lateiner das Wort serpens, Kriechend, als Bezeichnung der Schlange brauchten, so Kant gefragt werden, warum es ihnen nicht etwa 'Schnecke bedeute, denn auch diese ist ja serpens, (...) beide: serpens und Schnecke bezeichnen also durch eine nur einseitige Wahrnehmung die ganze und volle Anschaung". Meijers, A.; Stingelin, M. "Gerber und Nietzsche - Konkordanz". In: Nietzsche Studien, p. 355.

5. Nietzsche, F. Sobre verdade e mentira no sentido extra-moral. In: Sämtliche Werke. Kritische Studienausgabe, vol. I, p. 881. Em se atentando para a nota anterior, observa-se que também essa idéia está presente em Gerber. 
Vejamos as implicações desses três pontos da argumentação. Até aqui temos: uma tentativa de mostrar que, costumeiramente, tomamos impressões meramente subjetivas pelas próprias coisas; um empenho em delatar que, mesmo se tais impressões fossem suscitadas pelas coisas, jamais poderíamos saber se nessas impressões é conservada alguma característica das coisas tais como são em si mesmas.

O terceiro ponto da argumentação, referente à distinção entre as línguas, consiste numa comprovação dos dois primeiros pontos: tal diferença nos mostra que a palavra não é reflexo da própria coisa e, mesmo que seja uma conseqüência de qualquer espécie dela (isto é, que guardasse alguma relação de causalidade com ela), não manteria nenhuma de suas características essenciais.

Com isso, pode-se entender que Nietzsche concentra seus esforços no sentido de limitar o alcance da linguagem ao âmbito fenomênico ${ }^{6}$, e qualquer tentativa de lançá-la para além desse âmbito não passa de um procedimento antropomórfico, pois significaria projetar no exterior aquilo que é fruto de uma criação humana arbitrária e apenas tem sentido para o homem.

O segundo argumento, em favor da idéia de que a linguagem não está apta a alcançar as próprias coisas, erige-se sobre o fato de que o intelecto ${ }^{7}$ é apenas um instrumento de auto-conservação, não estando, por sua origem, apto a descobrir verdades. Tal intelecto "(...) foi concedido apenas como meio auxiliar aos mais in-

6. O final da primeira parte de Wabrheit und Luege evidencia que Nietzsche se apropria da noção de "fenômeno" em sua formulação schopenhaueriana: "Em geral, o que é para nós uma lei natural? Não a conhecemos em si, mas só pelos seus efeitos, isto é, nas suas relações com as outras leis da natureza, que por sua vez só são conhecidas por nós como conjunto de relações. Logo, todas estas relações não fazem mais do que reenviar constantemente de uma para a outra e, no que respeita a sua essência, são para nós completamente incompreensíveis; só aqueles com que contribuímos, o espaço, o tempo, isto é, relações de sucessão e de números, nos são realmente conhecidos." Nietzsche, F. Sobre verdade e mentira no sentido extra-moraI. In: Sämtliche Werke. Kritische Studienausgabe, vol. I, p 885.

7. O termo Intellekt, tão repetidamente utilizado por Nietzsche em Wahrheit und Luege, tem certamente um teor fisiologista tanto quanto em Schopenhauer. 
felizes, delicados e perecíveis dos seres, para firmá-los um minuto na existência, da qual, sem essa concessão, eles teriam toda razão para fugir tão rapidamente quanto o filho de Lessing". ${ }^{8}$ Apenas por um orgulho desmesurado poderia o homem ter chegado a ignorar a fugacidade de sua própria existência e a insignificância do intelecto cuja função está circunscrita a ela.

A inteligência humana, segundo Nietzsche, pode servir como meio de auto-conservação de duas formas. Primeiramente, enquanto meio de preservação do indivíduo em face de outros indivíduos que, porventura, se mostrem ameaçadores. Neste caso, o intelecto constrói um jogo dissimulador com o objetivo de enganar o outro:

O intelecto, como um meio para a conservação do indivíduo desdobra suas forças mestras no disfarce; pois é ele o meio pelo qual os indivíduos (Individuum) mais fracos, menos robustos, se conservam, aqueles nos quais está vedado travar uma luta pela existência com chifres ou presas aguçadas. ${ }^{9}$

8. Nietzsche, F. Sobre verdade e mentira no sentido extra-moral.In: Sämtliche Werke. Kritische Studienausgabe, vol. I, p 876. Heine, em sua Contribuição à História da Religião e Filosofia na Alemanha, cita a carta de Lessing a Theodor Eschenburg em que relata suas impressões sobre a morte do filho: "Minha alegria foi curta. E com que desgosto perdi esse filho! Você não acredita como as poucas horas em que fui pai já me transformaram num arremedo de pai! Sei o que estou dizendo. Não foi a inteligência que fez com que tivessem de trazê-lo ao mundo a fórceps que fez com que suspeitasse de tudo? Não foi a inteligência que fez com que aproveitasse a primeira ocasião para desaparecer de novo? (...)". Heine, H. Contribuição à História da Religião e Filosofia na Alemanha.Trad. de Márcio Suzuki. São Paulo: Iluminuras, 1991, p. 84. Esse trecho de Lessing não apenas ilustra o caráter fugaz da vida humana como, conseqüentemente, enfatiza o sentido efêmero da racionalidade a ela restrita, o qual, paradoxalmente, encontra sua função na conservação desta mesma vida. A grande sabedoria não está, no entanto, no intelecto enquanto servo dessa finalidade. Conforme já anunciava ao rei, o Sileno, na Origem da Tragédia, diz: “(...) a melhor coisa no mundo está fora de alcance: não ter nascido, não ser, não ser nada. Mas a segunda é, para você, morrer logo". Nietzsche, F. Die Geburt der Tragödie. In: Sämtliche Werke. Kritische Studienausgabe. vol.

3. Berlim: Walter de Gruyter, 1980, p. 35.

9. Nietzsche, F. Sobre verdade e mentira no sentido extra-moraI. In: Sämtliche Werke. Kritische Studienausgabe, vol. I, p.876. 
A segunda forma pela qual o intelecto serve à auto-conservação se apresenta

(...) quando o homem, ao mesmo tempo por necessidade e tédio, quer existir socialmente e em rebanho, ele precisa de um acordo de paz e se esforça para que pelo menos a máxima bellum omnium contra omnes desapareça de seu mundo. ${ }^{10}$

$\mathrm{Na}$ primeira maneira pela qual o intelecto se constitui como meio de auto-conservação, a inteligência serve unicamente para a conservação de um indivíduo, o que pode implicar a destruição de um outro; por meio da segunda, ela serve não apenas à conservação do indivíduo, como também da coletividade. Aqui a auto-conservação está condicionada à conservação da coletividade. Vale observar que Nietzsche atribui uma precedência da primeira em relação à segunda forma: antes, o homem desenvolvera o intelecto para o engano; posteriormente, por alguma razão (necessidade, tédio), ele condicionou sua sobrevivência à existência da paz no interior de um todo social.

Aqui já é delineada a primeira característica do intelecto humano: ele não é perene. Sua efemeridade se dá em dois níveis: num primeiro, por estar circunscrito à fugacidade da existência humana; num segundo nível, dado seu caráter utilitário, seu papel pode se transformar de acordo com as circunstâncias em que pode funcionar como meio de auto-conservação.

Enquanto meio de auto-conservação do indivíduo, a astúcia caracteriza a atividade do intelecto: sua tarefa está no ludibriar, no mascarar. Apenas por pura vaidade, por um apreço pelo que é superficial, enganoso, ilusório, fugaz, por ter ele próprio uma existência vã e efêmera, este homem se permite enganar-se sobre o alcance de seu intelecto, assim como o mesmo intelecto o teria enganado sobre o valor de suas "verdades". Assim, não se pode entender de que maneira se lhe imputou a função de buscar "verdades", ou seja, não se pode imaginar por que o homem que vive isoladamente atribuiria ao intelecto a tarefa de conhecer algo das coisas em si mesmas, pensa Nietzsche. É preciso, então, considerar o intelecto como instrumento de conservação da vida em coletividade, para verificar em que medi-

10. Idem, p. 877 . 
da o pendor à verdade, o Trieb zur Wabrheit, poderia ter descoberto aí seus fundamentos. Se, na existência isolada, o intelecto apenas engana, Nietzsche passa a considerar a possibilidade do impulso à verdade ter se originado juntamente com a instauração da sociedade: "Esse tratado de paz traz consigo aquilo que parece ser o primeiro passo para alcançar aquele enigmático impulso à verdade." ${ }^{11}$ Dado esse primeiro passo, a seqüência do trajeto do conhecedor está traçada:

agora, com efeito, é fixado aquilo que doravante deve ser 'verdade', isto é, é descoberta uma designação uniformemente válida e obrigatória das coisas, e a legislação dá também as primeiras leis da verdade: pois surge aqui pela primeira vez o contraste entre verdade e mentira. ${ }^{12}$

Quando o intelecto é utilizado como meio de conservação da coletividade, a linguagem é colocada a serviço da comunicação. Aí, cada membro do todo social deve usar as convenções lingüísticas de maneira correta, ou seja, ele deve "dizer a verdade", caso contrário estaria colocando em risco a segurança dos demais membros.

Nesse contexto, entretanto, "verdade" apenas pode ser compreendida como convenção estabelecida no âmbito da linguagem usada para a comunicação. O problema é que semelhante concepção de verdade não responde à pergunta inicial, que se voltava para a expectativa de que o conhecimento humano fosse habilitado para revelar-nos algo das coisas mesmas. Essa expectativa não é passível de justificações, pois “a verdade" alcançada no âmbito da comunicação reduz-se, no fim das contas, à veracidade:

o que os homens odeiam não é a ilusão, mas as conseqüências nocivas, hostis, de certas espécies de ilusões. E também em um sentido restrito semelhante que o homem quer somente a verdade: deseja as conseqüências da verdade que são agradáveis e conservam a vida. ${ }^{13}$

Se apenas "algumas ilusões" são rejeitadas, outras ilusões não o são. As últimas são chamadas "verdades". Portanto, querer a verdade aqui significa preservar apenas as ilusões que não causam da-

\begin{tabular}{ll}
\hline 11. & Idem, p. 887. \\
12. & Idem, p. 877. \\
13. Idem, p. 878.
\end{tabular} 
nos, que "conservam a vida" ao invés de ameaçá-la. Assim, a busca da verdade no domínio da existência em sociedade revela-se busca da veracidade e tem, então, um sentido meramente utilitário.

A determinação do "verdadeiro" aparece aqui submetida à legislação da linguagem. Entretanto, o uso do termo "legislação" (Gesetzgebung) indica que, se Nietzsche fala em "convenção", não se pode depreender disso um acordo entre partes nem uma deliberação comum no que diz respeito à fixação das denominações. O que há, na realidade, é um conjunto de normas a que todos se submetem a fim de evitar serem prejudicados. Trata-se de "uma designação uniformemente válida e obrigatória". Dessa forma, cada membro da coletividade deve limitar-se a usar a linguagem da forma sancionada pelo todo. Aquele que não respeitar tal legislação será chamado "mentiroso" e correrá o risco do banimento.

Com isso, Nietzsche não chega a uma resposta sobre qual seja o fundamento do Trieb zur Wahrheit, enquanto impulso voltado para conhecer as coisas em si mesmas, isto é, não chega a compreender por que via o conhecimento pode justificar - racionalmente - $\mathrm{o}$ motor de seu trabalho, qual seja: o pendor à verdade no sentido clássico de adequação. Pois, até aqui, falou-se em coerção à veracidade, o que difere de um impulso à verdade. No contexto social não se quer a verdade: é-se coagido a respeitá-la sob pena de sofrer punições (quando se mente) ou danos (quando se é enganado). Mas o que se alcança a esse respeito tampouco são "verdades", mas apenas a reiteração do universo lingüístico fixado a partir de uma coerção. Esse universo nada tem em comum com as "coisas" que busca designar.

Assim, entendemos que, para Nietzsche, tanto o caráter antropomórfico como o caráter utilitário do intelecto o tornam inapto a descobrir verdades, se por "verdade" for entendido um reflexo do mundo tal como é em si mesmo. Dessa forma, permanece sem resposta a pergunta pelo fundamento da expectativa de que o conhecimento apreenda as coisas em si mesmas.

Nietzsche quer apontar, através dessa discussão, para o fato de que o impulso à verdade não pode justificar-se racionalmente. Diante disso, a pergunta pela origem do Trieb zur Wabrheit, feita repetidamente pelo autor desde o início do texto, pode agora ser 
entendida como pergunta voltada para a gênese de uma crença. $\mathrm{E}$ a resposta vem de forma clara: "Somente por esquecimento pode o homem alguma vez chegar a supor que possui uma "verdade" no grau acima designado." ${ }^{14}$

Assim, a questão pode ser precisada da seguinte forma: quais os mecanismos que promovem a transformação do fixado em determinação do mundo tal como ele é em si mesmo, isto é, como se engendra a idéia de que há dados prévios à própria atividade do conhecimento, dados esses que justificariam a fixação da palavra? Trata-se, portanto, de compreender como ocorre o esquecimento de que toda palavra é mera criação arbitrária humana.

Em oposição ao impulso à verdade, característico do "homem racional", há o impulso artístico, presente no "homem intuitivo". Se o primeiro é escravo de finalidades externas (autopreservação da espécie), orienta-se para a conservação e busca a fixação, o segundo se satisfaz com a imediatez da atividade lúdica. Racionalidade e intuição se alternam em preponderância no decorrer dos diversos momentos históricos e das diferentes culturas. Enquanto a Grécia pré-socrática presenciou a vitória da segunda sobre a primeira, a época moderna, diz Nietzsche, vive o inverso:

Onde alguma vez o homem intuitivo, digamos como na Grécia antiga, conduz suas armas mais poderosamente e mais vitoriosamente do que o seu reverso, pode configurar-se, em caso favorável, uma civilização e fundar-se o domínio da arte sobre a vida (...). Nem a casa, nem o andar, nem a indumentária, nem o cântaro de barro denunciam que a necessidade os inventou: parece como se em todos eles fosse enunciada uma sublime felicidade e uma olímpica ausência de nuvens e como que um jogo com a seriedade..$^{15}$

A sociedade grega aparece aqui como modelo do mundo no qual a criação artística não sucumbe à posição de instrumento útil, no qual a arte "domina a vida" em vez de servir a ela como meio de conservação. O prazer lúdico dispensa a necessidade de qualquer justificativa:

14. Idem, p. 878 .

15. Idem, p. 890. 
O intelecto, esse mestre do disfarce, está livre e dispensado de seu serviço de escravo, enquanto ele pode enganar sem causar dano, e celebra então suas Saturnais. Nunca ele é mais exuberante, mais rico, mais orgulhoso e mais hábil e mais temerário: com prazer criador ele entrecruza as metáforas e desloca as pedras-limite das abstrações, de tal modo que, por exemplo, designa o rio como caminho em movimento que transporta o homem para onde ele, do contrário, teria de ir a pé. Agora ele afastou de si o estigma da servilidade (...)..$^{16}$

A arte é o lugar onde o intelecto se vê libertado da rigidez do pensamento conceitual ${ }^{17}$, o lugar onde seu trabalho não é pautado pela utilidade e pode, então, iludir, ludibriar livremente.

Assim, ainda que livre de sua atividade utilitária, ainda que livre de sua função de enganar para a sobrevivência, ele se dedicaria à ilusão como fonte de puro prazer estético ou lúdico. Essa atividade parece constituir o caráter original do intelecto, ficando

16. Idem, p. 890.

17. A tônica dessa segunda parte de Uber Wahrheit und Luege evidencia, de um lado, a presença do romantismo alemão (Schiller e Hölderlin), e, de outro, do idealismo de Iena (Schelling). A influência do primeiro se deixa revelar na apreciação do modelo da vida grega, em que, para Schiller, a arte proporcionava o verdadeiro equilíbrio entre a razão e a sensibilidade: na $12^{a}$. carta das Cartas sobre Educação Estética, o autor explicita a existência de dois impulsos opostos, sendo que "(...) o primeiro (o impulso sensível) constitui apenas casos, o segundo (impulso formal) fornece leis". Schiller, F. A educação estética do homem, carta XII, p. 69. O equilíbrio entre ambos, como se sabe, necessário à consecução do projeto ético schilleriano, será encontrado na arte. Esse equilíbrio pode ser reconhecido em Nietzsche como um equilíbrio de forças entre o homem racional e o homem intuitivo. Conforme observa Charles Andler (Cf. Andler, C. Nietzsche sa Vie et sa Pensée. Paris: Gallimard, 1958, v. I, L. I, cap. III, pp. 33-49), é muito expressiva a influência de Schiller sobre Nietzsche (Idem, p. 33). No que diz respeito ao ponto aqui mencionado, diz Andler: "Nossa barbárie moderna a mutila [a paixão sensível] pelo excesso de saber e de cálculo e nossa moral mesma está sem forças. (...) Apenas a arte sabe estabelecer entre a sensibilidade e a inteligência o equilíbrio feliz que é, concomitantemente, o natural e a liberdade. Schiller ensinou uma educação estética do gênero humano. Nietzsche definiu aí seu ponto de vista último como o prolongamento do esforço de Schiller. 'Meu objetivo é o objetivo de Schiller, mas elevado infinitamente"'. Idem, p. 39. 
a veracidade na condição de corrupção desse caráter resultante da vida em sociedade. "Dizer a verdade", em sociedade, nada mais é do que respeitar a mentira sancionada pelo todo. Até aqui não parece haver grande diferença entre esta e a atividade anterior do intelecto como meio de conservação, isto é, a atividade do intelecto enquanto expressão do Trieb zur Wahrheit. Lá também seu trabalho era o de enganar. Não há, no que se refere à sua atividade, oposição entre esses dois trabalhos do intelecto. Isso ocorre porque a verdadeira oposição não reside nos impulsos que o orientam. Quando o homem racional se sobrepõe ao homem intuitivo, o lado artístico desse impulso é, se não reprimido, ao menos mascarado, encoberto. Embora o impulso à verdade não possa efetivamente subjugá-lo, seu esforço se dá no sentido de fazê-lo. É então que, à semelhança do mecanismo de sublimação, aquele encontra na arte, vez por outra, via livre de expressão. $\mathrm{Na}$ atividade artística, é ainda o intelecto que engana: "O que quer que ele faça agora, tudo traz em si, em comparação com sua atividade anterior, o disfarce, assim como a anterior trazia em si a distorção." ${ }^{18}$

Apenas ocorre que, uma vez movido pelo impulso artístico, ele o faz livremente. A diferença, resultante disso, está em dois pontos: em primeiro lugar, como foi dito anteriormente, seus fins não são mediados, isto é, aqui ele não busca satisfazer finalidades externas ao seu produto mais imediato. Em segundo lugar, "ele copia a vida humana, mas a toma como uma boa coisa e parece darse por satisfeito com ela." ${ }^{19}$ Isso quer dizer que, à diferença do seu papel anterior, o intelecto tem aqui um papel positivo em relação à vida. Não se trata de conservá-la, não se busca evitar que ela se aniquile. Antes ele a exalta em sua forma efetiva. Assim, temos um primeiro ponto de distinção entre o impulso à verdade e o impulso artístico: embora a atividade do intelecto seja em ambas a mesma (o ludibriar), na primeira o seu resultado é pragmático - a conservação -, enquanto na segunda é estético - a elevação da vida à categoria de obra de arte. Vê-se, portanto, que a diferença da função

18. Nietzsche, F. Sobre verdade e mentira no sentido extra-moraI. In: Sämtliche Werke. Kritische Studienausgabe, vol. I, p. 888.

19. Idem, ibidem. 
do intelecto, enquanto servo de cada um daqueles impulsos, reside numa posição distinta com relação à vida. A idéia de "vida" é aqui tratada, por Nietzsche, como algo cuja referência está na idéia de efetividade, marcada pela imediatez e pela mutabilidade do devir heraclitiano. $\mathrm{Na}$ efetividade não há repetição no sentido estrito. Há somente "casos iguais" no plano do conceito:

Todo conceito nasce por igualação do não-igual. Assim como é certo que nunca uma folha é inteiramente igual a uma outra, é certo que o conceito de folha pelo abandono dessas diferenças individuais, por um esquecer-se do que é distintivo, e desperta então a representação, como se na natureza, além das folhas, houvesse algo que fosse "folha", uma espécie de folha primordial (..... ${ }^{20}$

Diante dessa "vida" identificada com a experiência efetiva da mutabilidade, o impulso à criação de metáforas (contrariamente ao impulso à verdade) não representa, nem em sua forma e tampouco em sua produção, nenhuma atitude negadora. Ao contrário, em seu conteúdo ele imita a vida e, na sua forma, ele próprio jamais encontra repouso em uma obra acabada, mas antes se incita pela possibilidade de substituí-la por outra:

Constantemente ele embaralha as rubricas e compartimentos dos conceitos, propondo novas transposições, metáforas, metonímias, constantemente ele mostra o desejo de dar ao mundo de que dispõe o homem acordado uma forma tão cromaticamente irregular, inconseqüentemente incoerente e eternamente nova como o mundo do sonho. ${ }^{21}$

A diferença reside no fato de que, quando voltado para a "verdade", o intelecto busca um objeto que apazigue sua atividade criadora, ou seja, ele quer algo, uma "verdade", que se sobreponha à mutabilidade da experiência. Assim, seu objetivo está em alcançar a perfeita negação da "vida", se por este termo for entendido "efetividade". Resta lembrar que, se ele o faz, isso ocorre no momento exato em que esse intelecto torna-se instrumento de conserva-

20. Idem, p. 880 .

21. Idem, p. 887. 
ção. $\mathrm{O}$ “impulso à verdade”, compreendido a partir dos elementos discutidos até aqui, caracteriza a reafirmação não apenas desta ou daquela denominação particular fixada, mas sim do fixo em geral:

Pode-se muito bem aqui, admirar o homem como um poderoso gênio construtivo, que consegue erigir sobre fundamentos móveis e como que sobre água corrente um domo conceitual infinitamente complicado (...). Ele é, aqui, muito admirável - mas só que não por seu impulso à verdade, ao conhecimento puro das coisas. ${ }^{22}$

A linguagem usada para a comunicação é, portanto, "convenção sólida" edificada sobre "água corrente". Partindo da idéia de que as denominações são forjadas a partir de modificações internas, a partir de estímulos nervosos, entende-se que o conceito fixo tem sua base no fluxo das impressões, o qual está em movimento constante. Pode-se, então, mensurar a distância que separa o impulso à verdade do impulso artístico criador de metáforas. Enquanto o primeiro busca o "fixado", tomando como legítima uma única metáfora em detrimento das outras tantas possíveis, o segundo constantemente cria e recria as figuras de linguagem e, ao fazê-lo, exalta a transformação e a multiplicidade da experiência efetiva.

O esquecimento a que se refere esse texto de Nietzsche é o esquecimento no sentido de que originalmente a palavra não visava à fixidez, mas servia para reproduzir o fluxo constante das impressões internas. Sendo esse fluxo um dado subjetivo, quando se busca fixá-lo não se erra, mas se mente. $\mathrm{O}$ homem mente, mas esquece o que faz:

mente, pois, da maneira designada, inconscientemente e segundo hábitos seculares - e justamente por essa inconsciência, justamente por esse esquecimento, chega ao sentimento de verdade. ${ }^{23}$

Há dois níveis do esquecimento: no primeiro, o sujeito esquece que os conceitos têm sua origem nas metáforas; mas esse esquecimento se sustenta sobre um outro nível, a saber, a inconsciência de que ele próprio reitera as ficções.

22. Idem, p. 882.

23. Idem, p. 881. 
No início do texto, Nietzsche enfatiza a idéia de que o homem nada pode saber sobre si mesmo, já que está encerrado no "cubículo de sua consciência" (Berwusstsein). ${ }^{24}$ Há, deduz-se, uma parte do próprio homem que escapa à sua consciência. No final da primeira parte, o autor observa que caso o homem pudesse, ainda que por apenas um instante, abandonar a crença de que às palavras corresponde algo em si, “(...) estaria imediatamente acabada sua 'autoconsciência' (Selbstberwusstsein)”. ${ }^{25}$ Aqui, existe uma associação entre a crença na palavra e a autoconsciência, a qual implica que, sendo superada a primeira, a segunda se destruiria.

Apenas para o "indivíduo", para o membro da coletividade, é que sujeito e consciência se identificam. É ele que entende tudo aquilo que escapa à sua consciência como determinação externa à ação humana. Ora, se percebesse que as palavras são meras criações arbitrárias humanas, ele teria de, imediatamente, atribuir a si mesmo o papel de artífice dessa criação, sobre a qual sua consciência não tem domínio. $\mathrm{O}$ esquecimento de que, na sua origem, a palavra é uma pura ficção se dá, conclui-se, em decorrência de um outro esquecimento, a saber, o esquecimento de si mesmo enquanto sujeito da criação artística. ${ }^{26}$

24. Idem, p. 877.

25. Idem, p. 883.

26. Há uma instância criadora inconsciente que, se ignorada, resulta em que se entenda ser a linguagem um produto dado aos homens a partir de instâncias alheias à sua atividade. Aqui se delineia a herança de Schelling sobre o pensamento de Nietzsche, presente nesse texto, a qual pode ser localizada na idéia de que o sujeito da criação artística não se identifica com a consciência e, conseqüentemente, projeta no exterior a determinação dos produtos daquela criação. Segundo Nicolai Hartmann, "Fichte tinha explicado a sua idealidade por meio da atividade irrefletida do Eu. Schelling aceita essa idéia em toda sua extensão, mas dá-lhe uma formulação mais feliz com o conceito de 'produção inconsciente'. O que aparece ao entendimento ingênuo como o limite do Eu em relação a um não-Eu independente é, na verdade, apenas o limite da consciência dentro do Eu. O sujeito não se reduz à consciência propriamente dita, necessita possuir um campo para os seus atos inconscientes; é preciso que haja nele, por assim dizer, um segundo plano inconsciente no qual se enraíze toda atividade espontânea”. Hartmann, N. A Filosofia do Idealismo Alemão. Trad. de José G. Belo. Lisboa: Calouste Gulbenkian, s/d, cap. 3, p.146. 
Com isso, a consciência não apenas não constitui um espelho capaz de refletir o mundo como é em si mesmo mas, indo além, Nietzsche a apresenta como véu encobridor do sujeito da criação artística (que extrapola o domínio da consciência). A consciência não é a instância que permite a superação do esquecimento, mas, ao contrário, sendo "orgulhosa e charlatã", pretende-se e apresenta-se como idêntica ao sujeito, o que a torna a sede do esquecimento por excelência: tudo aquilo que se apresenta como tendo sido engendrado independentemente dela passa a ser interpretado como determinação prévia em relação ao sujeito individual, às criações da coletividade, enfim, como dado anterior à ação humana em geral.

As considerações de Nietzsche sobre o antropomorfismo da linguagem, que agora podem ser consideradas de uma forma mais aprofundada, buscam exatamente delatar a ausência de fundamentos para a nossa crença no transcendente. Aquilo que à percepção sensível aparece como determinado a partir de instâncias externas nada mais é do que o produto de uma criação inconsciente, produto esse que, por uma série de transposições, apresenta-se como "coisa", "objeto", de tal forma acabado que toma a feição de reflexo ou efeito do "em si". O impulso à verdade é uma força que impele justamente à apreensão desse presumido objeto, cuja legitimação deve ser dada pela transcendência. Portanto, parece legítimo compreender esse impulso como um pendor em direção ao fixo em geral, tendência que pode ser interpretada como busca do "dado". ${ }^{27}$

Se isso explica o motor do esquecimento do sentido original da palavra como criação artística, o que engendra o pendor de tomá-la como reflexo das próprias coisas, cabe agora perguntar pelo motor desse processo. Diante dessa nova meta, o seguinte trecho pode ser esclarecedor:

No sentimento de estar obrigado a designar uma coisa como "vermelha", outra como "fria", uma terceira como "muda", desperta uma emoção

27. Esse termo, estranho ao escrito aqui abordado, será utilizado com o objetivo de ressaltar que o Trieb zur Wahrheit não apenas busca o fixado, mas o "fixo" e "previamente determinado". 
que se refere moralmente à verdade (...) [o homem] coloca agora seu agir como ser "racional" sob a regência das abstrações; não suporta mais ser arrastado pelas impressões súbitas, pelas intuições. ${ }^{28}$

Da "obrigação" se desenvolve uma "emoção". O membro da comunidade é, num primeiro momento, coagido a utilizar cada metáfora da maneira fixada pelo todo social e, num segundo momento, passa a ver com repulsa não apenas todas as outras criações metafóricas que reivindicam a designação daquela mesma experiência mas, sobretudo, repugna-lhe assentir ao fluxo constante de suas próprias impressões internas. Para não ser "arrastado pelas intuições", num movimento de auto-engano que, aí sim, indiferencia impulso à verdade de impulso artístico, cria-se a idéia de aparência enganosa, como véu encobridor da substância fixa que se esconderia por detrás delas.

A pergunta pelo motor do esquecimento pode, portanto, ser dividida em duas outras perguntas: a primeira, relativa à razão do mal-estar provocado pela experiência da mutabilidade; a segunda, voltada a esclarecer o que haveria de "moral" nessa repulsa.

Detenhamo-nos, por ora, na primeira pergunta. Nietzsche entende que o mundo empírico não é um dado. Conforme já visto, uma vez ultrapassada a crença na determinação prévia dos conceitos, a própria consciência que nela crê se encontra ameaçada. A atitude diante das vivências internas se repete no que diz respeito à consciência: sua origem é desconhecida e, como conseqüência, projetada em alguma instância transcendente. Entretanto, o fato de que a consciência seja incapaz de apreender sua própria origem não autoriza a afirmar que ela não esteja submetida ao vir-a-ser. Assim como a idéia de antropomorfismo buscava explicar de que maneira se engendra a crença no mundo objetivo, da mesma forma a noção de utilitarismo surge, nesse texto, para questionar a idéia acerca da indeterminação da consciência. A consciência não é transparente para si mesma porque é instrumento de conservação do todo social e, enquanto tal, apreende unicamente o mundo

28. Nietzsche, F. Sobre verdade e mentira no sentido extra-moraI. In: Sämtliche Werke. Kritische Studienausgabe, vol. I, p. 881. 
circunscrito pelos estreitos limites da linguagem. Ela serve à comunicação e, portanto, seus fins lhe escapam, pois são determinados pelas necessidades da coletividade.

Para a consciência, questionar o dado significaria questionarse a si mesma, significaria suspeitar do conhecimento que ela pode ter de si própria. No que diz respeito ao apreço pela verdade fixa imutável, essa consciência não é apenas sua reprodução: ela é sua própria encarnação, pois se considera um dado. Assim, o que essa consciência quer, ao supor o dado, é ignorar a fugacidade de sua própria existência. A crença no dado permite a essa consciência preservar a crença em sua própria perenidade. Assim, a mutabilidade da experiência intuitiva é repulsiva por denunciar a efemeridade do próprio indivíduo que vivencia. Ela coloca em xeque a perenidade da consciência.

No que se refere ao sentido moral dessa repulsa, voltemos alguns passos atrás na discussão sobre a consciência. Uma vez que o impulso à verdade é experimentado pela consciência como busca "desinteressada", evidencia-se que, para essa consciência, não há escolha entre querer ou não a verdade. Ela busca o fixo, mas o que lhe escapa é o fato de o valor da fixidez ser previamente determinado. Para dizer de outro modo, o impulso à verdade quer o dado, mas a consciência posta a seu serviço se acredita dispensada de justificar a necessidade do fixo, já que, pressupondo sua validade, entende que o conhecimento apenas pode dar-se por ocasião de sua apreensão. A consciência nem ao menos poderia voltar seus esforços no sentido de buscar fundamentos racionais para o valor do dado que ela objetiva alcançar, uma vez que ela é, para si própria, um dado e, assim, questioná-lo significaria suspeitar de sua própria legitimidade, isto é, colocar a si mesma em questão. Enfim, o impulso à verdade aparece na consciência como pendor ao fixo previamente determinado. Entretanto, a própria consciência, como construto, já é fruto desse impulso, uma vez que vê a si mesma como dada.

$\mathrm{Na}$ medida em que o impulso à verdade promove a reiteração do valor dado, mas, concomitantemente, se mostra incapaz de colocar em questão o valor desse mesmo dado por ele buscado, pode-se compreender esse impulso à verdade como a própria ne- 
cessidade do dado. O problema se torna moral pelo fato de que à consciência é vedado reconhecer que tal necessidade é engendrada pela ação dos homens no seio da vida em coletividade. Trata-se de uma coerção ao fixado que é por ela vivenciada como apreço pela "verdade", apreço que encobre a necessidade do dado. Escapa-lhe, enfim, que seu impulso à verdade é resultante de uma certa configuração de forças no interior da existência social e que o valor da fixidez é resultante de uma norma socialmente imposta.

Diante do temor da dissolução da consciência, o indivíduo - o membro do todo social a ela identificado - desenvolve em si um sentimento de afeição pela norma. Ele tem uma tendência "espontânea" a reafirmá-la, tendência calcada sobre a crença em sua própria perenidade. Isso explica o que faz com que o valor da verdade seja progressivamente distanciado de sua utilidade original - a coerção à veracidade -, e passe a se impor de forma absoluta. O sentido fixado da palavra é buscado como algo independente das relações humanas, como algo determinado para além dessas relações, porque tal independência é a condição para que se possa acreditar na perpetuidade da existência humana.

É possível, então, compreender aquilo que Nietzsche denomina questão "moral" como a introjeção da lei por meio de um valor que produz uma emoção. Emoção situada no temor da auto-aniquilação vivenciado pelo indivíduo identificado com sua consciência.

Dessa forma, respondemos à pergunta anteriormente formulada pelo motor do impulso à verdade: pode-se agora concluir que, sendo tal impulso um pendor à necessidade do dado no sentido acima descrito, tal necessidade deve seu aparecimento à preservação do todo social. Na medida em que ela não pode aparecer como tal à consciência individual, e não pode fazê-lo como condição mesma de sua própria conservação, tomar a necessidade do dado como válida per se (e não como necessidade circunscrita a um determinado momento histórico) significa a introjeção das normas sociais por meio de um sentimento.

Com isso se explica por que surge o impulso à verdade: é necessário que cada membro da coletividade respeite as formas fixadas e, para que esse respeito não seja quebrado, cria-se a ilu- 
são de que a validade dessas formas antecede as ações humanas e é dada por fatores externos a essas ações, ou seja, incute-se na comunidade a crença de que essa validade é determinada pela correspondência entre palavra e coisa, o que resulta em que ela se apresente aos homens como inquestionável.

Se não há adequação, tampouco há convenção que seja capaz de legitimar a fixidez na linguagem. A fixação dos termos é resultante de um impulso que extrapola o terreno abarcado pela consciência, o que impede a consecução de um acordo intersubjetivo sobre o uso da linguagem. Além disso, entretanto, a consciência representa a instância de reprodução das regras socialmente impostas, na medida em que é o solo sobre o qual se sustenta o esquecimento.

Finalmente, tal concepção deflagra um problema moral, visto que toda discussão sobre os limites do conhecimento travada pelo autor termina por se revelar voltada para o questionamento de um valor absoluto atribuído à verdade. Mostrar a arbitrariedade da linguagem resulta na construção da suspeita de fixidez na linguagem. Conseqüentemente, o que Nietzsche realmente faz é delatar a necessidade do dado que move todo trabalho do conhecimento. Esse é o sentido da pergunta inicial acerca da origem do Trieb zur Wabrheit. Uma vez que essa necessidade é resultante de uma lei social, mas, ao mesmo tempo, é vivenciada subjetivamente como impulso espontâneo, o problema em questão diz respeito ao âmbito da moral.

A partir disso, é possível afirmar que Nietzsche não está realmente preocupado com o alcance do conhecimento racional. Sua preocupação se volta para o campo da moral: somente isso justificaria seu tratamento das questões de teoria do conhecimento, as quais, do ponto de vista da problemática moral, acabam por configurar um pseudoproblema, um sintoma de um problema maior e anterior. Levar "a sério" a discussão sobre a possibilidade de alcançar as coisas em si mesmas, presente no início de Wahrheit und Luege, significaria legitimar a preocupação com o referencial externo que o próprio autor delata como sendo reflexo da "necessidade do dado", isto é, como fruto do impulso à verdade. 
Dessa forma, qualquer tentativa no sentido de situar a discussão central de Wabrheit und Luege no âmbito da teoria do conhecimento significaria apenas uma nova reiteração da necessidade do dado. Isso porque, segundo Nietzsche, quando se discute a possibilidade de apreensão da essência das coisas ou da coisa em si, já se toma o referencial externo como determinante daquilo que se entenderá por "conhecimento". Entretanto, a validade de tal referencial não pode ser justificada racionalmente, ou seja, não pode ser conhecida no âmbito da consciência. Sendo tal validade estabelecida no terreno da moral, terreno este que impulsiona o próprio trabalho do conhecimento racional, a teoria do conhecimento não pode se posicionar criticamente diante dela.

Ernst Behler, ao comparar a crítica nietzschiana ao pensamento conceitual com a crítica à racionalidade feita pelo Romantismo de Iena, faz uma importante ressalva em relação a hipervalorização da arte nesses autores:

(...) se eles criticam a hegemonia da ciência e da filosofia (...), eles não parecem, absolutamente, postular o outro extremo, uma hegemonia da arte, mas antes uma reciprocidade, uma alternância entre metáfora e conceito, entre arte e ciência. ${ }^{29}$

Diante disso, é possível entender que Nietzsche julga necessário exaltar o impulso artístico enquanto contraponto da hipertrofia do impulso à verdade existente na cultura moderna e que a aproxima da barbárie.

Quanto à noção de verdade suposta em Sobre verdade e mentira, vê-se que Nietzsche situa suas preocupações, já em 1872-3, para além das discussões sobre a possibilidade de uma adequação entre representação e coisa, entre signo e significado, para mostrar que também esse tipo de pergunta já é expressão do impulso à verdade que, originalmente um impulso artístico, tornou-se, se não corrompido, ao menos décadent.

29. Behler, E. "Nietzsche et la philosophie du langage du romantisme d'Iena". Trad. de Volker Schröder. In: Philosophie, no. 27, 1990 (7), p. 62. 


\section{BIBLIOGRAFIA:}

ANDLER, C. Nietzsche, sa vie et sa pensée. Paris: Gallimard, 1958.

BEHLER, E. "Nietzsche et la philosophie du langage du romantisme d'Iena”. Trad. de Volker Schröder. In: Philosophie. Paris: Minuit, $\mathrm{n}^{\circ}$. 27, $1990(7)$.

HABERMAS, J. "La Critica Nihilista del Conocimiento en Nietzsche". In: __ Sobre Nietzsche y otros ensayos. Trad. de Carmen G. Trevijano e Silverio Cerra. Madri: Tecnos, 1982.

HARTMANN, N. A Filosofia do Idealismo Alemão. Trad. de José G. Belo. Lisboa: Calouste Gulbenkian, s/d.

HEINE, H. Contribuição à História da Religião e da Filosofia na Alemanha. Trad. de Márcio Suzuki. São Paulo: Iluminuras, 1991.

HERDER, J. G. Ensaio Sobre a Origem da Linguagem. Trad. de José M. Justo. Lisboa: Antígona, 1987.

MEIJERS, A.; STINGELIN,M. “Gerber und Nietzsche-Konkordanz". In: Nietzsche Studien, v. XVII, 1988.

. "Gustav Gerber und Friedrich Nietzsche". In: Nietzsche Studien, v. XVII, 1988.

NIETZSCHE, F. Obras Incompletas. Trad. de Rubens Rodrigues Torres Filho. São Paulo: Abril Cultural, 1978.

Sämtliche Werke. Kritische Studienausgabe. Berlim: Walter de Gruyter, 1980.

SCHILLER, F. A Educação Estética do Homem. Trad. de Roberto Schwartz e Márcio Suzuki. São Paulo: Iluminuras, 1990. 